$06.4 ; 03.5$

\title{
Высокоскоростное взаимодействие металлической струи с керамикой
}

\author{
(C) Б.В. Румянцев, С.И. Павлов \\ Физико-технический институт им. А.Ф. Иофффе РАН, Санкт-Петербург, Россия \\ E-mail: brum@mail.ioffe.ru
}

Поступило в Редакцию 30 апреля 2020 г.

В окончательной редакции 30 апреля 2020 г.

Принято к публикации 25 мая 2020 г.

Исследуется дестабилизация кумулятивной струи с начальной скоростью более $8 \mathrm{~km} / \mathrm{s}$ при внедрении в хрупкие материалы. С помощью электронной микроскопии анализируется состояние остатков материалов в каверне. Наблюдаемые фазовые превращения меди и хрупких материалов в остаточной каверне свидетельствуют о высоких температурах в области внедрения и раскрывают влияние термодинамических параметров взаимодействующих материалов на дестабилизацию высокоскоростного внедрения.

Ключевые слова: высокоскоростной удар, металлическая струя, хрупкие материалы, плавление, испарение, защита.

\section{DOI: 10.21883/PJTF.2020.17.49885.18363}

Изучение внедрения металлических струй в конденсированные среды имеет большое практическое значение при решении задач защиты от высокоскоростного удара со скоростью $2-10 \mathrm{~km} / \mathrm{s}$ [1-4]. В лабораторных условиях высокоскоростную металлическую струю (ВМС) получают при детонации зарядов взрывчатых веществ, содержащих коническую воронку. В настоящей работе рассматриваются особенности взаимодействия металлической струи с начальной скоростью более $8 \mathrm{~km} / \mathrm{s}$ с хрупкими материалами (карбид кремния, ультрафарфор). В отличие от металлов (дюраль АМГ6) (рис. 1) внедрение ВМС в хрупкие материалы (ХМ) осложняется радиальным действием откольных масс с поверхности каверны в преграде [2,4-10]. Схема эксперимента по исследованию внедрения кумулятивной струи [6] представлена на рис. 1, где введены следующие обозначения: 1 - устройство формирования струи с медной воронкой диаметром $d=20 \mathrm{~mm}$ и углом $30^{\circ}, 2$ - преграда из пластин дюраля АМГб размером $10 \times 60 \times 60 \mathrm{~mm}$ (плотность $2.64 \mathrm{~g} / \mathrm{cm}^{3}$ ) или карбида кремния размером $20 \times 80 \times 80 \mathrm{~mm}$ (плотность $3.0 \mathrm{~g} / \mathrm{cm}^{3}$ ), 3 - контактные датчики измерения времени внедрения струи $t$ на глубине $L$. Эксперимент проводился в вакуумной камере при давлении менее $20 \mathrm{kPa}$. Экспериментальные результаты внедрения в дюраль (кружки) и карбид кремния (крестики) приведены на расчетной диаграмме $L-t$, где штриховая кривая - расчет внедрения в преграду в одномерном гидродинамическом приближении $[3,6]$; сплошная кривая - траектория схлопывания кумулятивной воронки; сетка наклонных линий - траектории движения элементов струи со скоростью $V_{j}$. Экспериментальная кинетика внедрения ВМС в ХМ отличается приостановкой и возобновлением внедрения с увеличением времени и уменьшением глубины поглощения (рис. 1). Преодоление области схлопывания вызывает приостановку траектории проникания и дестабилизацию последующих элементов струи. В результате систематических исследований действия медной струи с начальной скоростью $6.5 \mathrm{~km} / \mathrm{s}$ на высокопрочные XМ [5,6] было установлено, что относительная способность снижения глубины поглощения струи по сравнению с металлами определяется прочностью к изгибу.

Результаты численного моделирования [11] внедрения медной струи в карбид кремния показывают область схлопывания каверны, после прохождения которой элементы струи диспергируются, смешиваются с откольными фрагментами карбида кремния и заполняют весь объем каверны.

Нарушение гидродинамического характера внедрения в ХМ отражает дестабилизацию ВМС.

Возможность получения высоких скоростей кумулятивных струй при уменьшении угла воронки позволяет создавать высокие давления до $100 \mathrm{GPa}$, что, очевидно, будет усиливать дестабилизацию процесса проникания BMC в XМ, влиять на параметры защиты от высокоскоростного удара.

Цель настоящей работы - исследование последствий дестабилизации медной струи с начальной скоростью $8.3 \mathrm{~km} / \mathrm{s}$ при внедрении в хрупкие материалы.

Для этого на сканирующем электронном микроскопе (SEM) анализировались остатки материала, заполняющего каверну после окончания внедрения струи. Для сохранения каверны был взят цилиндр из ультрафарфора УФ-46 (смесь корунда и оксида кремния плотностью $3.2 \mathrm{~g} / \mathrm{cm}^{3}$ ) диаметром $50 \mathrm{~mm}$ и длиной $100 \mathrm{~mm}$ в стальной оболочке диаметром $100 \mathrm{~mm}$. Вскрытая каверна содержала пористую массу красного (медного) цвета, которая частично заполняла весь объем. Отдельно были видны застывшие медные капли размером $0.1-0.3 \mathrm{~mm}$. 


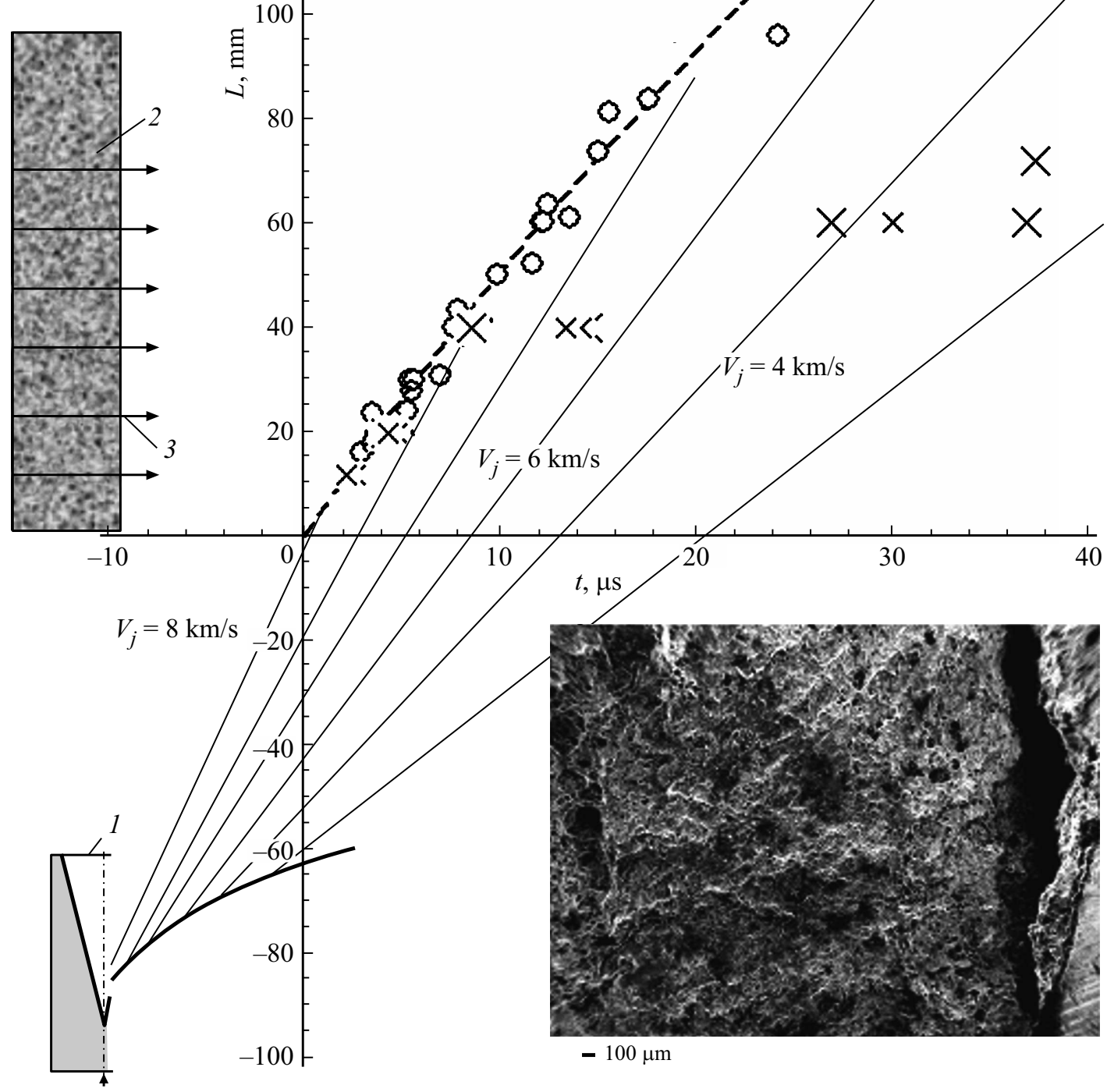

Рис. 1. Сравнение внедрения медной струи в дюраль (кружки) и карбид кремния (крестики). Конечные глубины внедрения 150 и $70 \mathrm{~mm}$ в дюраль и карбид кремния соответственно. На вставке - SEM-изображение поверхности каверны в АMГ6.

На рис. 2, 3, $a$ представлены SEM-изображения затвердевших сфероподобных медных частиц в матрице ультрафарфора с различным состоянием поверхности: — с открытой пористостью размером $\sim 15 \mu \mathrm{m}$ (рис. 2); - со сплошной структурированной поверхностью размером $\sim 200 \mu \mathrm{m}$ (рис. $3, a)$.

При увеличении разрешения на сплошной поверхности проявляется картина затвердевания двухкомпонентной смеси (рис. $3, b, c$ ), состоящей из сферических частиц ультрафарфора размером $100-300 \mathrm{~nm}$ и ориентированных на них удлиненных медных частиц размером до $100 \mathrm{~nm}$. Рыхлые светлые агрегаты идентифицированы как окись меди.

Наличие в каверне крупных сфероподобных частиц меди свидетельствует о разрушении струи при радиальном схлопывании откольных фрагментов ультрафарфора с поверхности каверны. При схожих условиях внедрения в дюраль сфероподобные частицы меди не наблюдаются (вставка на рис. 1). Все частицы имеют повреждения, полученные в результате динамических перемещений в объеме образовавшейся каверны. Морфология поверхности частиц отражает многообразие форм и параметров взаимодействия с ультрафарфором в зависимости от места и времени. Например, на поверхности медных частиц (рис. 2) проявляются „замороженные“ поры кипящей жидкой меди, другая часть более крупных медных частиц имеет относительно гладкую, структурированную при охлаждении поверхность (рис. $3, a$ ), которая покрыта „замороженным“ слоем расплавленных частиц ультрафарфора и сконденсированных на них парах меди. Идентификация состава сфер (окислы кремния, алюминия) и окружающих частиц (медь) на рис. 3,c и рыхлых светлых агрегатов на рис. $3, b$ производилась методом рентгеноструктурного микроанализа (RSMA).

Характер структуры между зернами свидетельствует о том, что сферические частицы расплавленного уль- 
$a$

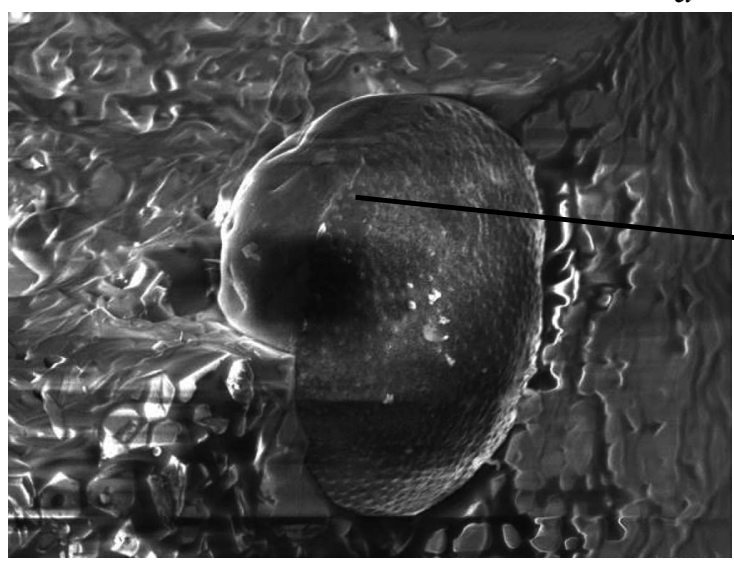

$-1 \mu \mathrm{m}$

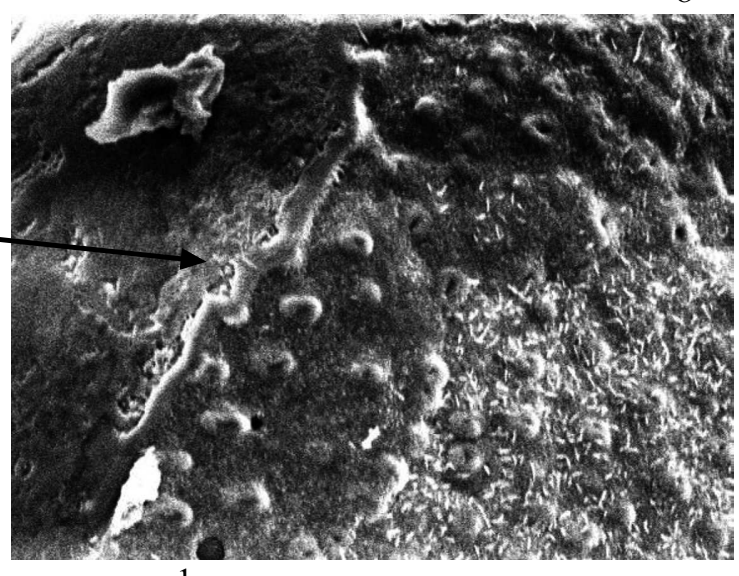

Рис. 2. $a-$ медная частица в матрице хрупкого материала, $b-$ поры на поверхности застывшей медной капли.

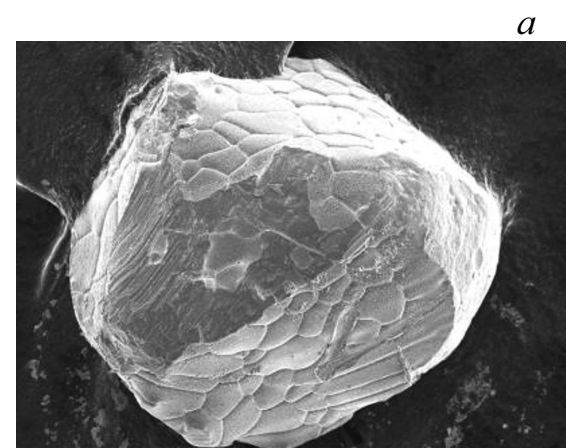

$-10 \mu \mathrm{m}$



$-1 \mu \mathrm{m}$ $b$

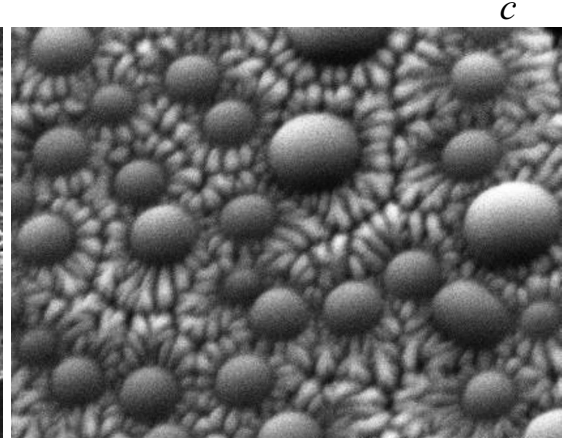

- $100 \mathrm{~nm}$

Рис. 3. $a-$ затвердевшая медная частица с поверхностной структурой на уровне $10-50 \mu \mathrm{m}, b-$ структура поверхностного слоя частицы с аморфным слоем окиси меди, $c$ - „замороженная“ структура кристаллизации паров меди на каплях ультрафарфора размером $100-300 \mathrm{~nm}$.

трафарфора являются центрами „конденсации“ для паров меди.

SEM-изображение поверхности крупных частиц раздробленной струи (рис. 3) свидетельствует об „идеальном“ смешении (постоянство размера структуры, периодичность), что достигается в парах меди. Побочный результат окисления меди, по-видимому, продуктами детонации устройства 1 (рис. 1) подтверждает вывод о парообразном, „активном“ состоянии меди.

Качественное отличие наблюдаемого состояния поверхности частиц отвечает частицами из разных областей каверны и с различной степенью взаимодействия с материалом преграды.

Основные состояния поверхности капель струи после охлаждения - совокупность пор кипящей меди в „горячих“ частицах размером 10-20 $\mu \mathrm{m}$ и картина осаждения на более крупных „холодных“ частицах смеси паров меди и жидких капель ультрафарфора. Представленные состояния свидетельствуют о динамическом разогреве локальных областей до температур более $3000 \mathrm{~K}$ [11]. Наиболее вероятные места локального разогрева - это область прохождения ВМС через схлопывающийся материал каверны и области скольжении меди относительно стенок каверны. Можно сделать вывод, что высокая температура плавления и низкая теплопроводность ХМ [12] поддерживают температуру на уровне температуры испарения материала струи, способствуют увеличению длительности процесса взаимодействия и уменьшению глубины внедрения.

Глубокое взаимодействие ВМС в ХМ обсуждалось в работе [7], где исследовались сохраненные остатки медной струи с начальной скоростью $7.8 \mathrm{~km} / \mathrm{s}$ после внедрения в стекло и кварц. В то же время приведенные кинетические результаты внедрения не отражают последствий этого взаимодействия.

Максимальное давление на начальной глубине внедрения при скорости медной струи $8-6 \mathrm{~km} / \mathrm{s}$ в ультрафарфор составляет $60-70 \mathrm{GPa}$, что явно недостаточно для ударного разогрева меди до температур испарения. Установленное наличие испаренной меди свидетельствует о дополнительном разогреве при неадиабатическом 
сдвиговом взаимодействии с ультрафарфором на стенках и в области радиального схлопывания $[7,11,13]$.

Таким образом, при внедрении ВМС в ХМ высокая прочность обеспечивает схлопывание откольного слоя каверны, возмущение и разрушение струи. В местах значительных градиентов скоростей между ВМС и ХМ возникают локальные области разогрева. Последующее проникание приобретает объемный характер. При этом проявляется влияние тепловых свойств ХМ на поглощение кумулятивных струй.

Радиальная реакция керамической преграды при внедрении ВМС создает условия для нарушения гидродинамического характера проникания и эффективного преобразования направленной кинетической энергии струи в тепловую.

\section{Конфликт интересов}

Авторы заявляют, что у них нет конфликта интересов.

\section{Список литературы}

[1] Rosenberg Z., Dekel E. Terminal ballistics. Springer, 2016. 359 p. https://www.springer.com/us/book/9789811003936

[2] Частные вопросы конечной баллистики / Под ред. В.А. Григоряна. М.: Изд-во МГТУ им. Н.Э. Баумана, 2006. Гл. 5.

[3] Физика взрыва / Под ред. Л.П. Орленко. М.: Физматлит, 2002. T. 2. 832 c.

[4] Held M. // Prop. Expl. Pyrotechn. 1998. V. 23. P. 105-110.

[5] Румянцев Б.В. // ФТТ. 2011. Т. 53. В. 10. С. 2018-2022.

[6] Румяниев Б.В. // ЖТФ. 2019. Т. 89. В. 5. С. 685-691. DOI: $10.21883 /$ JTF.2019.05.47469.337-18

[7] Hauver G.E., Netherwood P.H., Bensk R.F., Melani A. Penetration of shaped-charge jets into glass and crystalline quartz. Technical report BRL-TR-3273. Maryland: U.S. Army Ballistic Research Laboratory, Aberdeen Proving Ground, 1991. $56 \mathrm{p}$.

[8] Hornemann U., Holzwarth A. // Int. J. Impact Eng. 1997. V. 20. P. $375-386$.

[9] Moran B., Glenn L.A., Kusubov A. // J. de Phys. IV (France). 1991. V. 1. P. C3-147-C3-154.

[10] Zhang X.-F., Li Y.-C., Yu S.-J. Numerical study on penetration process of multi-layer ceramic target by shaped charge jets // Proc. of Int. Conf. on mechanical engineering and mechanics (ICMEM 2007). Wuxi, China, 2007. http://www.paper.edu.cn/scholar/showpdf/ MUT2MNOIMTD0Ix0h

[11] Rumyantsev B.V., Klimenko V.Yu. // AIP Conf. Proc. 2012. V. 1426 . P. $56-59$. DOI: $10.1063 / 1.3686220$

[12] http://thermalinfo.ru/svojstva-materialov/keramika-i-steklo/

[13] Zhu D., Zheng Z., Chen Q. // Mater. Sci. Eng. A. 2014. V. 595. P. 241-246. https://doi.org/10.1016/J.MSEA.2013.12.025 